\title{
Correction to: Corticospinal excitability is altered similarly following concentric and eccentric maximal contractions
}

\author{
Pierre $\operatorname{Clos}^{1}\left([) \cdot\right.$ Yoann Garnier $^{1,2}(\mathbb{C}) \cdot$ Alain Martin $^{1} \cdot$ Romuald Lepers $^{1}(\mathbb{C}$
}

Published online: 17 February 2021

○) Springer-Verlag GmbH Germany, part of Springer Nature 2021

\section{Correction to:}

\section{European Journal of Applied Physiology}

(2020) 120:1457-1469

https://doi.org/10.1007/s00421-020-04377-7

The original version of this article unfortunately contained a mistake. The correct information is given below.

In Fig. 2, the torque loss corresponding to $\mathrm{CON}_{\mathrm{W}}$ is not $14.5 \pm 14.5$ but $36.9 \pm 14.5$. More torque is thus lost in this condition than in $\mathrm{ECC}_{\mathrm{F}}$. The corrected Fig. 2 is given in the following page.
In the "Results" section, the last sentence of the following section "Fatigue during the dynamic exercise" should read: Dynamic peak torque loss was more pronounced in CON than ECC for the completion of the same work. It was $15.0 \pm 14.6 \%$ superior in CONW than ECCF $(P=0.02$; $\mathrm{dz}=1.02)$, and $13.4 \pm 7.0 \%$ superior in CONF than ECCW $(P<0.001 ; \mathrm{dz}=1.92)$.

The original article can be found online at https://doi.org/10.1007/ s00421-020-04377-7.

Pierre Clos

Pierre.Clos@u-bourgogne.fr

1 INSERM UMR1093-CAPS, Université Bourgogne FrancheComté, UFR des Sciences du Sport, 21000 Dijon, France

2 Clermont-Auvergne University, AME2P, Clermont-Ferrand, France 


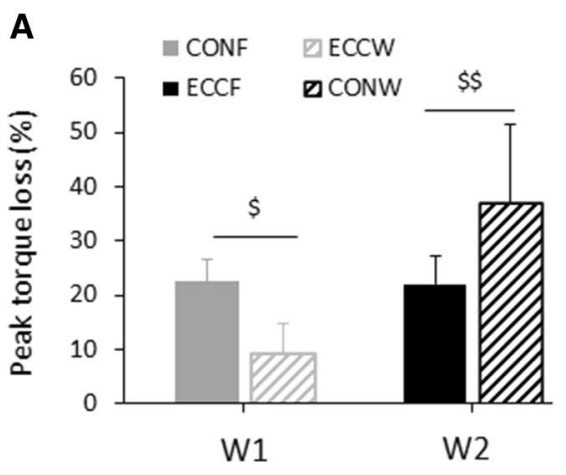

B Start of exercise

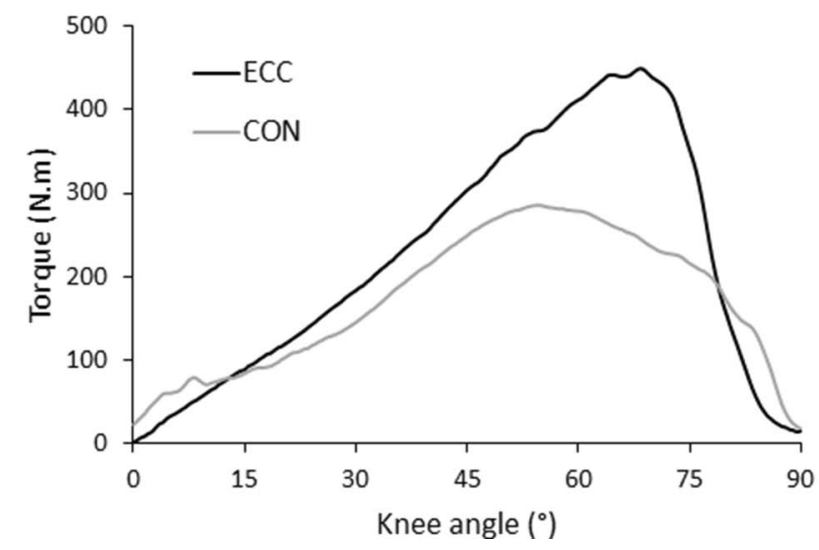

Fig. 2 The panel a shows the decline in dynamic peak torque from the three first to the three last contractions of the exercise. The values are expressed as a percentage of those of the three first contractions of the first set of the same session. Sessions matched for work are illustrated in the same color (grey versus black). The panel $\mathbf{b}$ displays the evolution of the torque with knee angle during one maximal knee extension of a typical subject during an ECC and a CON contraction at the beginning and the end of the exercise. Different from the condition matched for work at a given time: ${ }^{\$}$ means $P<0.05 ;{ }^{\$}$ means

Publisher's Note Springer Nature remains neutral with regard to jurisdictional claims in published maps and institutional affiliations.

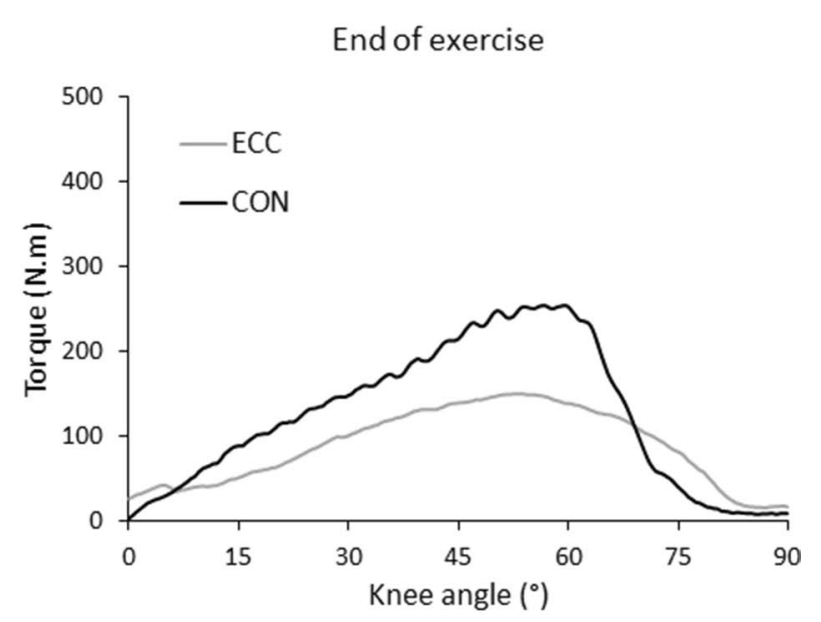

$P<0.01$. $E C C_{F}$ ECC contractions performed until $20 \%$ of dynamic torque loss, $C_{F} \mathrm{CON}$ contraction performed until $20 \%$ of dynamic torque loss, $E C C_{W}$ ECC contractions performed until having completed the same work as in $\mathrm{CON}_{\mathrm{F}}, C_{W} \mathrm{~N}_{W} \mathrm{ECC}$ contractions carriedout until having completed the same work as in $\mathrm{ECC}_{\mathrm{F}}$. Work 1 (W1) corresponds to the $10.2 \pm 5.3 \times 10^{3} \mathrm{~J}$ performed in $\mathrm{ECC}_{\mathrm{F}}$ and $\mathrm{CON}_{\mathrm{W}}$, and Work 2 (W2) refers to the $5.8 \pm 5.9 \times 10^{3} \mathrm{~J}$ completed in $\mathrm{CON}_{\mathrm{F}}$ and $\mathrm{ECC}_{\mathrm{W}}$ 